\title{
Metastatic Ovarian Serous Adenocarcinoma
}

National Cancer Institute

\section{Source}

National Cancer Institute. Metastatic Ovarian Serous Adenocarcinoma. NCI Thesaurus.

Code C160782.

Ovarian serous adenocarcinoma that has spread from its original site of growth to another anatomic site. 